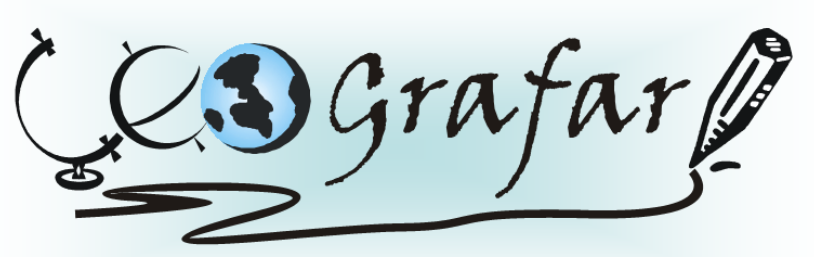

Revista Eletrônica do Programa de Pós-Graduação em Geografia - UFPR

\title{
COMPLEXOS EÓLICOS E INJUSTIÇAS AMBIENTAIS: \\ MAPEAMENTO PARTICIPATIVO E VISIBILIZACCÃO DOS CONFLITOS PROVOCADOS PELA IMPLANTAÇÃO DE PARQỦES EÓLICOS NO CEARÁ
}

\section{WIND-ENERGY COMPLEX AND ENVIRONMENTAL INJUSTICE: PARTICIPATIVE MAPPING AND VISUALIZATION OF CONFLICTS IN THE IMPLANTATION OF WIND-ENERGY COMPLEX IN CEARÁ}

\author{
Lígia Alves Viana \\ Mestranda em Desenvolvimento e Meio Ambiente \\ Universidade Federal do Ceará \\ Fortaleza, CE, Brasil \\ e-mail: ligiaviana@gmail.com

\begin{abstract}
João Luís Joventino do Nascimento
Mestre em Educação

Universidade Federal do Ceará

Fortaleza, CE, Brasil

e-mail:joaodocumbe@yahoo.com.br
\end{abstract}

\begin{abstract}
Antônio Jeovah de Andrade Meireles Prof. Dr. do Departamento de Geografia Universidade Federal do Ceará

Fortaleza, CE, Brasil e-mail:meireles@ufc.com.br
\end{abstract}

\begin{abstract}
RESUMO
O Estado do Ceará tem intensificado os investimentos para o mercado de suprimentos energéticos através de política(s) de desenvolvimento caracterizada(s) por incentivos à implantação de grandes indústrias e agroindústrias. Este estudo tem como objetivo analisar conflitos e (in)justiças ambientais ocasionados pela implantação de Parques Eólicos na Zona Costeira do Ceará por meio da experiência de intercambio entre comunidades que ocorreu em 2014 no Assentamento Maceió e ainda pautando os impactos socioambientais que podem advir com a implantação do projeto do Complexo Eólico Baleia no entorno do Assentamento Maceió, localizado no município de Itapipoca/CE. Para tanto, o percurso metodológico foi baseado em pesquisa participante e elaboração de mapa dos conflitos provocados por parques
\end{abstract}




\title{
VIANA, L. A.; NASCIMENTO, J. L. J.; MEIRELES, A. J. A \\ COMPLEXOS EÓLICOS E INJUSTICAS AMBIENTAIS: \\ MAPEAMENTO PARTICIPATIVO E VISIBILIZACÃ̃O DOS CONFLITOS \\ PROVOCADOS PELA IMPLANTAÇÃO DE PARQUES EÓLICOS NO CEARÁ
}

eólicos no Ceará, por meio do mapeamento participativo e diálogo de saberes entre as comunidades, de modo a identificar os impactos sociais e ambientais impostos às comunidades pelos parques eólicos já implantados e as estratégias de garantia e defesa do território.

Palavras-chave: Energia Eólica, Conflitos Ambientais, Mapeamento Participativo, Intercâmbio de Experiências

\begin{abstract}
The state Ceará has intensified investments also for energy supplies market through its development policy characterized by incentives for the deployment of large scale industries and agribusinesses. This study has aimed to analyze conflicts and environmental (in)justices caused by the deployment of wind-energy parks in Ceará's Coastal Zone through the exchange of experiences between communities in 2014 in Maceió's settlement and also guiding social and environmental impacts that may arise with the deployment of wind-energy Complex Baleia, surrounding the Maceió's settlement, Itapipoca's municipality- Ceará. For this, the methodological approach was based on participatory research and preparation of conflicts map caused by wind-energy parks in Ceará through participatory mapping and a dialogue of knowledge between communities in order to identify social and environmental impacts imposed to communities by wind-energy parks already deployed, and estrategies of assunrance and defense of territory.
\end{abstract}

Keywords: Wind-energy, Environmental conflicts, Participatory mapping, Exchange of experiences.

\section{INTRODUÇÃO}

Com a crise de 2008, o país reforça suas estratégias econômicas baseadas na exportação de commodities num processo de ampliação das fronteiras de produção homogeneizadoras. Com esse crescimento na produção primária, essencialmente para exportação, há a intensificação pela demanda em investimentos em infraestrutura, visando à expansão da produção nacional voltada, sobretudo, para o agronegócio e grandes indústrias transnacionais.

Esse contexto impulsionou a prática de investimentos e incentivos voltados para os empreendimentos que garantissem a estrutura energética para a manutenção dessa dinâmica de produção e consumo. As estratégias adotadas pelo Governo Federal, através da Política Nacional de Energia, após avaliação das bases institucionais do sistema elétrico e da crise energética do país em 2001, consistiram 


\section{VIANA, L. A.; NASCIMENTO, J. L. J.; MEIRELES, A. J. A. \\ COMPLEXOS EÓLICOS E INJUSTIÇAS AMBIENTAIS: \\ MAPEAMENTO PARTICIPATIVO E VISIBILIZAÇÃO DOS CONFLITOS \\ PROVOCADOS PELA IMPLANTAÇÃO DE PARQUES EÓLICOS NO CEARÁ}

num modelo que tornasse o setor competitivo e atrativo para investimento privado ${ }^{1}$ no campo da geração e comercialização de energia. O lançamento do Programa de Incentivo a Fontes Alternativas (PROINFA), através da Lei 10.438/2002, objetiva a ampliação da participação de fontes renováveis no país. Na segunda fase do Programa a contratação de energia no país ocorre em leilões de energia que seguem por dois ambientes de mercado: Ambiente de Contratação Livre (ACL) e Ambiente de Contratação Regulada (ACR). Em 2009 ocorre o primeiro leilão de energia específico para a fonte eólica.

Nesse sentido, frente à crescente demanda por suprimentos energéticos, o Governo Federal estruturou um modelo institucional voltado para a diversificação dessa matriz, com financiamentos liberados junto ao Banco Nacional de Desenvolvimento (BNDES) e ações previstas no Programa de Aceleração do Crescimento (PAC).

O Estado do Ceará, através de sua política de desenvolvimento caracterizada pelos incentivos à implantação de grandes indústrias e agroindústrias, tem intensificado os investimentos também para o mercado de suprimentos energéticos. Com o objetivo de atrair capitais internacionais foi contratado um estudo para avaliação do potencial eólico do Estado, intitulado Atlas do Potencial Eólico do Estado do Ceará, publicado em 2001, pela Secretaria de Infraestrutura (SEINFRA).

A zona costeira do Estado do Ceará é apresentada, nessa perspectiva, como área com grande potencial eólico a qual, aliada aos incentivos fiscais dos Governos Federal e Estadual para implantação de grandes complexos eólicos, constitui-se, um atrativo não apenas para investidores internacionais, mas também para empresas estatais. Desde então, os processos de implantação de Complexos Eólicos no Estado do Ceará cresce exponencialmente na região costeira, avançando inclusive para além da costa, seguindo para áreas de serras e chapadas.

É importante considerar nesse processo a intervenção na dinâmica dos territórios, ocasionada pela implantação dos grandes empreendimentos eólicos. A

\footnotetext{
${ }^{1}$ Na década de 1990 ocorreu a implantação de programa de privatizações e abertura da economia para o investimento estrangeiro configurando ao Estado uma função de regulador do mercado através das agências, no caso do setor energético, a Agencia Nacional de Energia Elétrica (ANEEL). Porém, diante da conjuntura geopolítica mundial, o país adota uma série de estratégias de inserção no mercado mundial por meio de uma política neodesenvolvimentista. O Estado passa, assim, a ser mediador dos processos, submetendo-se às pressões do capital e ainda a ser empreendedor diante da implantação de grandes obras de infraestrutura para garantir o avanço de fronteiras produtivas.
} 
implantação dos Complexos Eólicos representa uma intervenção que altera não só a paisagem, mas os modos de vida nas comunidades. É relevante investigar como essa intervenção influência nas formas de produção, na cultura, nas relações territoriais e perspectivas de vida nessas comunidades.

O investimento em obras de grande porte e planos de desenvolvimento voltados para o crescimento econômico reflete a conjuntura descrita e instiga a participação no debate sobre os aspectos que configuram o avanço das fronteiras produtivas sobre as comunidades tradicionais e os bens naturais destes territórios. Nesse sentido, este estudo procura analisar os processos de conflitos e (in)justiças ambientais ocasionados pela implantação de Parques Eólicos na Zona Costeira do Ceará por meio da experiência de intercambio entre comunidades que ocorreu em 2014 no Assentamento Maceió e ainda pautando os impactos socioambientais que podem advir com a implantação do projeto do Complexo Eólico Baleia no entorno do Assentamento Maceió, localizado no município de Itapipoca/CE. Para tanto, o percurso metodológico foi baseado em pesquisa participante, elaboração de mapa dos conflitos provocados pela instalação de parques eólicos no Estado do Ceará através do mapeamento participativo e diálogo de saberes entre as comunidades de modo a identificar os custos sociais e ambientais impostos às comunidades locais impactadas com parques eólicos já implantados, e estratégias locais de garantia e defesa do território.

\section{Desenvolvimento Sustentável e justiça ambiental: onde está o viés?}

O cenário histórico aponta diversos episódios de crises econômicas que apresentam um caráter sistêmico (PAULA, 2010; LISBOA, 2014) de períodos de reinvenção e atualização de estratégias para manutenção do ciclo de produção e consumo próprios da lógica hegemônica do capitalismo.

A partir da década de 60 questionamentos sobre a viabilidade da relação entre desenvolvimento e crescimento econômico são expressas em diversos estudos ${ }^{2}$, e a questão ambiental torna-se tema em destaque diante das consequências do modo de produção e consumo do mundo capitalista que conduzem a um cenário de incertezas

\footnotetext{
${ }^{2}$ Dentre outros estudos, na época destacaram-se o Relatório Limites do Crescimento de Meadows e Meadows de 1972 e o Nosso Futuro Comum expresso pela Comissão Mundial Sobre Meio Ambiente e Desenvolvimento, em 1987, conhecido como Relatório de Brundtland, com intensa repercussão e que marcam a inserção da pauta no mundo.
} 


\section{VIANA, L. A.; NASCIMENTO, J. L. J.; MEIRELES, A. J. A. \\ COMPLEXOS EÓLICOS E INJUSTIÇAS AMBIENTAIS: \\ MAPEAMENTO PARTICIPATIVO E VISIBILIZACCÃO DOS CONFLITOS \\ PROVOCADOS PELA IMPLANTAÇÃO DE PARQUES EÓLICOS NO CEARÁ}

sobre os limites do padrão produtivo hegemônico. Desde a Revolução Industrial, o processo produtivo ocorre com intensa utilização de bens naturais e exploração das populações nos países ditos periféricos que possibilitam o ciclo de crescimento econômico dos países centrais. Assim, com a crise ambiental, esse debate tem assumido lugar central na geopolítica global.

O processo de institucionalização dessa temática perpassa uma trajetória de conferências mundiais cujo debate assume, num cenário de correlação de forças e interesses em disputa, uma visão hegemônica acerca do uso de recursos naturais e a finitude dos mesmos. Desde a Conferência de Estocolmo em 1972, a concepção de desenvolvimento sustentável aponta para uma perspectiva de compatibilização das questões sociais e ambientais às estratégias hegemônicas de mercado. Para PortoGonçalves (2012), a concepção de desenvolvimento sustentável consiste em uma "nova forma de colonização/exploração" no qual submete o desenvolvimento tecnológico à ideia de dominação da natureza.

Assis (2011) argumenta que o sentido de apropriação da natureza está relacionado às disputas por imposições de "noções simbólicas e materiais de meio ambiente" que confere um conjunto de significados ao modo capitalista de produção como único caminho para a vida humana. Nesse sentido, a ideia de desenvolvimento sustentável tem sido estratégia fundamental para legitimar a expansão produtiva, utilizando-se da concepção de que através da eficiência tecnológica se alcançará o uso racionalizado dos recursos territoriais, seguindo como suporte ao avanço do capitalismo sobre os territórios.

Assim, na conjuntura atual, vimos configurar-se uma hegemonia caracterizada pela expansão da produção e consumo, visando construir estratégias de acumulação frente a um cenário de debates sobre a capacidade do planeta de suportar a aceleração dos fluxos de energia e matéria provocados pela imposição da economia sobre as dimensões sociais, culturais e ambientais.

A expansão das fronteiras produtivas sobre os territórios tradicionais ocorre com processos de distribuição desigual dos danos causados pelos grandes empreendimentos produtivos. No processo de avanço de grandes empreendimentos impõe-se, assim, a estes territórios a condição de "zonas de sacrifício" (ACSERALD, 2009) como consequência da perpetuação de um modelo de desenvolvimento que geram injustiça ambiental e intensificam conflitos. A apropriação dos espaços e bens 


\section{VIANA, L. A.; NASCIMENTO, J. L. J.; MEIRELES, A. J. A \\ COMPLEXOS EÓLICOS E INJUSTIÇAS AMBIENTAIS: \\ MAPEAMENTO PARTICIPATIVO E VISIBILIZACÃ̃O DOS CONFLITOS \\ PROVOCADOS PELA IMPLANTAÇÃO DE PARQUES EÓLICOS NO CEARÁ}

naturais, com fins de desenvolvimento pautado numa visão econômica de acumulação financeira, atingem populações e povos em seus direitos territoriais ocasionando expropriação nessas comunidades.

A Rede Brasileira de Justiça Ambiental define, em sua Declaração de Lançamento, o conceito de injustiça ambiental como:

[...] o mecanismo pelo qual sociedades desiguais, do ponto de vista econômico e social, destinam a maior carga dos danos ambientais do desenvolvimento às populações de baixa renda, aos grupos sociais discriminados, aos povos étnicos tradicionais, aos bairros operários, às populações marginalizadas e vulneráveis. (RBJA, 2001, p.01)

Acserald et al (2009) apontam que os elementos que configuram a desigualdade ambiental apresentam-se através dos aspectos de acesso aos bens naturais e da proteção ambiental. No âmbito do acesso aos bens naturais, na perspectiva da produção, a implantação de grandes empresas e obras de infraestrutura para o desenvolvimento ocasionam a inviabilização das formas nãocapitalistas de produção. Povos e comunidades tradicionais sofrem os impactos decorrentes dessas atividades produtivas enquanto as empresas inseridas numa conjuntura hegemônica de mercado utilizam como mecanismo de atuação, "relações de privilégio com o poder público".

A dimensão dos impactos sobre as comunidades tendem a tornarem-se invisíveis nos processos de licenciamento ambiental, sobretudo através do subdimensionamento das implicações ambientais e sociais apontadas nos Estudos de Avaliação de Impactos contratados pelas empresas com fins de obtenção de autorização para instalação dos empreendimentos. Diversos estudos e pareceres revelam a omissão, durante o processo de licenciamento, dos impactos sobre comunidades tradicionais diretamente afetadas por grandes empreendimentos e a adoção de uma concepção que caracteriza como zonas de vazios demográficos, áreas histórica e culturalmente ocupadas ${ }^{3}$. Dentre os estudos e pareceres existentes destacamos: Meireles et al, (2009) em “O povo Indígena Anacé e seu Território Tradicionalmente Ocupado (Parecer Técnico № 01/09 ao Ministério Público Federal e Procuradoria da República no Estado do Ceará); Santos e Hernandez (2009) em "Painel de Especialistas: Análise Crítica do Estudo de Impacto Ambiental do aproveitamento Hidrelétrico de Belo Monte".

\footnotetext{
${ }^{3}$ Questões identificadas inclusive durante a análise do Estudo de Impacto Ambiental do Complexo Eólico Baleia, realizado neste estudo conforme apresentado mais adiante.
} 


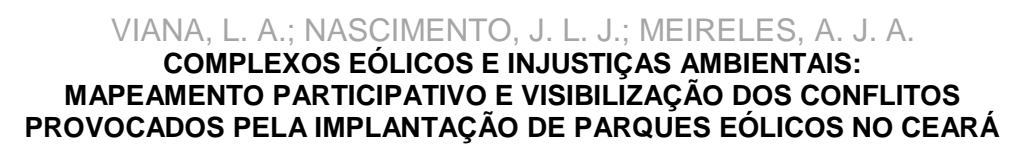

É importante destacar que grandes empreendimentos que utilizam intensivamente bens naturais geram poucos empregos (Acserald et al, 2009) e avançam sobre territórios nos quais as comunidades desenvolvem práticas produtivas, que estão fora da lógica hegemônica de mercado (Porto-Gonçalves, 2012) e que garantem dinâmica social de um contingente significativos de sujeitos. Nesse sentido, um contingente expressivo da população também está fora do padrão de consumo imposto pelo modo de produção hegemônico baseado na acumulação de capital e com acesso desigual aos bens. A desigualdade ambiental está associada à apropriação desigual dos bens naturais e ainda, para além, aos mecanismos de apropriação desses bens e suas formas de uso.

No âmbito da proteção ambiental, os elementos que caracterizam esse processo de desigualdade estão relacionados aos interesses de mercado associados aos mecanismos de desinformação com esvaziamento político do debate e processos de neutralização da crítica. A desigualdade ambiental é justificada por diversas estratégias que seguem o discurso de negação da injustiça ambiental. São estratégias de argumentação baseadas na perspectiva de legitimar práticas empresariais degradantes que expropriam as populações de seus territórios e buscam instrumentos para garantir seus interesses e controlar as reações das populações afetadas em lutas por justiça ambiental.

A gestão e controle dos conflitos são elementos considerados estratégicos nos setores empresariais que buscam instrumentos como: refutação das críticas, investimento em canais de comunicação que oportunamente produzem dúvidas e informações desencontradas, confusas e inacessíveis; estabelecimento de relações com a comunidade, oferta de brindes e abordagem individual junto aos moradores; práticas de negociação de conflitos com investimentos em tecnologias de resolução de conflitos; esvaziamento político do debate sobre as implicações do empreendimento nos territórios; separação das relações ambientais e sociais no processo de avaliação de impactos e implantação do empreendimento.

É importante considerar o caráter da assimetria de poder nos processos de mediação de conflitos no qual é beneficiado quem está favorável na correlação de forças com maiores possibilidades de barganha de interesses. Nesse sentido, ocorre uma despolitização do conflito, exercendo assim, a resolução de conflitos, um papel desmobilizador (Acserald et al, 2009). 


\section{VIANA, L. A.; NASCIMENTO, J. L. J.; MEIRELES, A. J. A. \\ COMPLEXOS EÓLICOS E INJUSTIÇAS AMBIENTAIS: \\ MAPEAMENTO PARTICIPATIVO E VISIBILIZACÃ̃O DOS CONFLITOS \\ PROVOCADOS PELA IMPLANTAÇÃO DE PARQUES EÓLICOS NO CEARÁ}

Frente aos processos e táticas de avanço das fronteiras produtivas sobre os territórios, gerando desigualdade e injustiça ambiental, tem-se as frentes de resistência social, que seguem em luta para garantir as formas de fazer e de viver que estão fora da lógica hegemônica de produção. O modo de produção capitalista avançado encontra nas práticas da agricultura familiar camponesa, nas comunidades tradicionais como povos indígenas e quilombolas, comunidades pesqueiras e demais grupos sociais que vivem processos contra-hegemônicos de produção, estratégias de resistência e de mobilização crítica em torno da luta em defesa dos territórios. Porém, com a intensificação dos projetos de infraestrutura e investimentos em grandes obras, construir um debate político quanto a essa conjuntura incide sobre a questão da atuação do Estado enquanto estruturante no processo de implantação de grandes empreendimentos e na garantia de interesses privados como discutiremos no tópico seguinte.

\section{A questão Energética e o Desenvolvimento no Estado do Ceará}

Diante da política nacional de incentivos através inicialmente do PROINFA e financiamentos disponibilizados pelo BNDES ${ }^{4}$ associado ao seu potencial, o Governo do Estado do Ceará investe cada vez mais em empreendimentos eólicos. Com o intuito de atrair investidores a Agencia de Desenvolvimento do Estado do Ceará (ADECE) elaborou um Atlas do Potencial Eólico do Estado. O documento identifica que o Ceará tem alta capacidade produtiva nesta fonte energética, com geração de 35 mil megawatts (MW), sendo 25 mil MW em terra (onshore) e 10 mil MW no mar (offshore).

Em 2014, o Governo do Estado do Ceará anuncia que pretende atualizar os dados, apontando para a atração de mais investidores e expansão de instalações neste setor. Segundo o Presidente da Câmara Setorial de Energia Eólica do Ceará ${ }^{5}$ da ADECE, a capacidade de geração de energia eólica no Estado pode chegar a 50mil MW. Esse crescimento do potencial deve-se ao fato de que o estudo realizado em

\footnotetext{
${ }^{4}$ A Lei $n^{\circ} 10.438$ de 26 de abril de 2002 cria o Programa de Incentivo às Fontes Alternativas de Energia Elétrica - PROINFA como incentivo às políticas de diversificação da matriz energética com base em fontes eólicas, pequenas centrais hidrelétricas e biomassa base em fontes eólicas, pequenas centrais hidrelétricas e biomassa.

${ }^{5}$ Informação disponível em: http://www.opovo.com.br/app/opovo/economia/2014/08/27/noticiasjornal economia,3304496/governo-vai-atualizar-atlas-eolico-por-cerca-de-r-600-mil.shtml. Acesso em $\underline{22 / 06 / 2015}$.
} 


\section{VIANA, L. A.; NASCIMENTO, J. L. J.; MEIRELES, A. J. A. \\ COMPLEXOS EÓLICOS E INJUSTIÇAS AMBIENTAIS: \\ MAPEAMENTO PARTICIPATIVO E VISIBILIZACCÃO DOS CONFLITOS \\ PROVOCADOS PELA IMPLANTAÇÃO DE PARQUES EÓLICOS NO CEARÁ}

2001 utilizou dados com base em torres de $50 \mathrm{~m}$ de altura e, para a atualização dos dados em 2014 foram consideradas torres que ultrapassam 100m. De acordo ainda com a ADECE , só em 2009, durante o primeiro leilão de energia eólica, foram arrematados no Ceará 21 das 71 usinas do país previstas para operação em 2012.

Desde então o processo de expansão de parques eólicos implantados ao longo da zona costeira intensificou-se e ocupa extensos territórios. Num exercício de levantamento e agrupamento dos dados disponíveis pela Empresa de Pesquisas Energéticas/EPE e Secretaria de Meio Ambiente do Ceará/SEMACE sobre as usinas em operação, em teste, em construção e licenciadas, existem cerca de 1.400 aerogeradores ocupando uma área total de cerca de 25.200 ha $^{6}$.

O cenário de expansão de parques eólicos no Estado aponta para um crescimento exponencial incluindo um avanço para o interior do Estado como na Serra da Ibiapaba e Chapada do Apodi. Segundo dados da EPE (2015), estão atualmente em operação 59 usinas eólicas no Estado do Ceará 15 usinas em construção, e previstos ainda mais 47 parques com construção ainda não iniciada totalizando uma previsão de 121 usinas em operação até 2018.

Os dados disponibilizados pela EPE revelam que até 2018 a geração de energia por fontes eólicas expandirá de forma exponencial no Estado do Ceará. Isso representa um processo de expansão intenso e que ocasiona uma série de conflitos e injustiças ambientais que atualmente são foco de questionamentos sobre a viabilidade dessa geração no modelo de implantação de torres em larga escala ocupando extensos territórios. Para que e para quem essa energia é produzida e até que ponto é legitimo populações serem sacrificadas para a geração de riqueza e acumulação de capital para grandes empresas e instituições de financiamento multilaterais ${ }^{7}$ são questionamentos apontados pelas comunidades afetadas e movimentos sociais sobre a questão energética e avanço de grandes empreendimentos no país.

As estratégias de desenvolvimento para o país, pautadas na extração de bens naturais, no avanço de fronteiras produtivas através de um intenso processo de expropriação de territórios de comunidades tradicionais, são debates que estão no

\footnotetext{
${ }^{6}$ Fonte: Levantamento documental próprio através de dados da Secretaria de Meio Ambiente do Estado do Ceará/ SEMACE e Empresa Pesquisa Energética/EPE, 2015.

7 Parques de Energia Eólica, Conflitos e Injustiças Ambientais na Zona Costeira - Carta das Comunidades e organizações da sociedade civil elaborado durante o I Seminário Energia Eólica, Conflitos e Injustiças Ambientais realizado em 2012.
} 


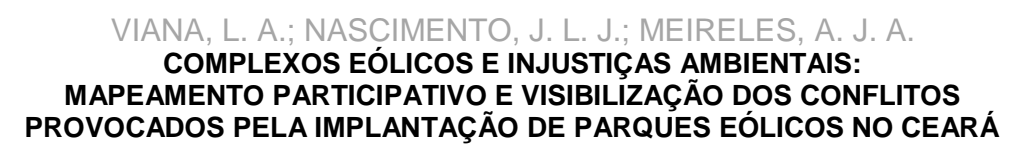

centro das tensões entre os movimentos sociais e o processo de implantação de grandes empreendimentos de infraestrutura.

Os impactos ocasionados pela implantação dos parques eólicos estendem-se para além da intervenção no curso para aves migratórias e mortandade de morcegos como muito expressado nos Estudos de Impacto Ambiental e Relatório de Impacto Ambiental/EIA/RIMA apresentados. Os diversos impactos são apontados por pesquisadores, movimentos sociais e pelas próprias comunidades que historicamente vivem nos territórios onde são implantados os parques eólicos. Estudos de Meileres (2011), Freitas (2012), Porto, Finamore e Ferreira (2013) e Brissac e Santos (2014) apontam a implantação de parques eólicos como geradores de impactos, conflitos e de injustiças ambientais.

Meireles (2011) identificou, na região litorânea do Ceará, os diversos impactos ocasionados pela implantação de parques eólicos em área de dunas. A alteração na dinâmica costeira é causada pelo conjunto de atividades de fixação de aerogeradores na região, desde o desmatamento, compactação do solo e terraplenagem para construção de vias de acesso à soterramento de lagoas interdunares, fixação artificial de dunas, alteração do curso de dunas móveis num processo de fragmentação dos ecossistemas.

\section{"Um povo unido seu Dr. não há quem possa"8}

O II Seminário Energia Eólica, Injustiças e Conflitos Ambientais nos Territórios Tradicionais e Camponeses realizado em maio de 2014 pelo Instituto Terramar, Universidade Federal do Ceará com parceria da Associação de Moradores do Imóvel Maceió/ASCIMA e Associação de Cultivadores(as) de Algas do Maceió/ACALMA, representa momento importante com relação a articulação social para a visibilidade dos impactos sociais e ambientais e construção de estratégias de resistência quanto a implantação dos Complexos Eólicos nas comunidades costeiras do Estado do Ceará.

O evento foi realizado no Assentamento Maceió no município de Itapipoca e contou com a participação de diversas comunidades da zona costeira impactadas ou

\footnotetext{
${ }^{8}$ Verso da música "Xote do Acampamento" do agricultor e compositor Antonio Sousa - Assentamento Maceió em Itapipoca.
} 
não pela instalação dos parques de energia eólica. A estratégia fundamental do seminário é a de promoção de intercâmbio de informações sobre a situação das diversas comunidades quanto a implantação dos Complexos Eólicos. Sobretudo, considerando que no entorno do Assentamento Maceió a implantação de mais um Complexo com 58 torres, foi através do intercâmbio que, por exemplo, as comunidades do assentamento e entorno tiveram acesso a informações sobre o processo de implantação de parques eólicos e seus impactos. A ausência de informações sobre os projetos, dentre outras violações, é uma das táticas utilizadas pelas empresas responsáveis pela implantação dos empreendimentos.

Através da troca de experiência e de relatos dos/as moradores/as das comunidades atingidas pela implantação dos complexos eólicos, bem como com as avaliações técnicas apresentadas com a presença de pesquisadores da Universidade Federal do Ceará, foi traçado um perfil dos impactos e estratégias das empresas para implantação dos parques eólicos.

A estratégia da cartografia social mostrou-se neste momento um instrumento fundamental na construção da síntese e expressão dos impactos e estratégias levantadas pelas comunidades participantes do intercâmbio representando um processo elaborado a partir das comunidades afetadas. Como discute Acserald:

Se o mapeamento participativo se pretende parte de um projeto de ordem científica, visando a questionar os pressupostos ocultos da ciência da informação geográfica no que diz respeito as seus efeitos sociais, seu eventual sucesso enquanto tal deve estar associado a processos concretos de democratização do território e do acesso a seus recursos e não à configuração de uma simples expressão espacial da ideologia do desenvolvimento. (ACSERALD, 2008, p. 41)

O resultado desse momento é ilustrado pela figura 1. 


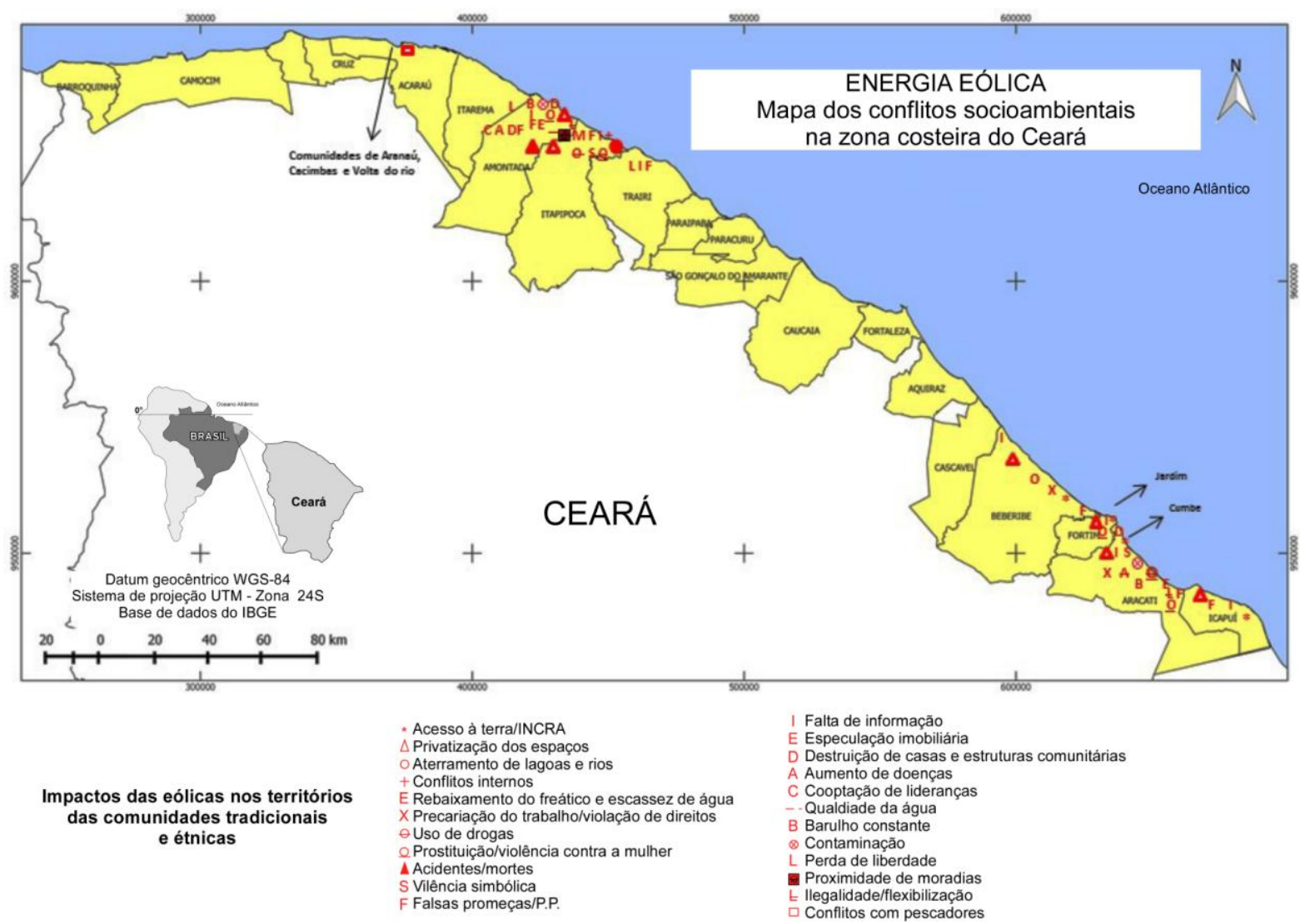

Figura 1 - Mapa comunitário com levantamento dos impactos elaborado pelas comunidades intercambiantes no Seminário. Digitalização: Laboratório de Geoprocessamento - Departamento de Geografia - UFC, 2014.

\section{A instalação e permanência dos Complexos Eólicos nas comunidades} costeiras apresentam influencia direta na qualidade de vida da população, na cultura, na paisagem e na perspectiva de vida local. Identifica-se problemas ambientais por conta da instalação desses empreendimentos no campo de dunas, soterramento de lagoas interdunares, rebaixamento do lençol freático, destruição de sítios arqueológicos e mudança no deslocamento e fixação das dunas, interferência nas rotas de aves migratórias.

Meireles (2008) apresenta em seus estudos os impactos ambientais da implantação de parques eólicos em campos de dunas.

... os impactos relacionados com a atividade de implantação serão incrementados na fase de operação, isto devido á necessidade de manutenção da rede de vias de acesso que interliga cada um dos aerogeradores e da instalação e permanência dos demais equipamentos de acompanhamento e monitoramento da usina. Fora que esses impactos serão potencializados devido à dinâmica de migração das areias na direção dos equipamentos, bem como a necessidade de controle do soterramento das vias de acesso e dos próprios aerogeradores pelas dunas móveis. (MEIRELES, 2008 p. 46) 
Essas interferências têm reflexo direto nas atividades tradicionais realizadas pela população como, por exemplo, na mobilidade dos sujeitos locais, no qual não podem mais seguir livremente pelo território sendo impedidos pelo processo de privatização das áreas de passagem e uso das comunidades, a exemplo da proibição de acesso às lagoas onde antes se constituíam espaços de lazer e de pesca, áreas de cultivo de subsistência e comprometendo a qualidade das fontes de água para consumo.

\footnotetext{
Nossa água vem da Lagoa dos Cavalos, água tá salobra, foi jogada para o mar, antes nunca secava, o tamanho do impacto que tem no lençol freático devido as grandes estruturas das bases para segurar a torre da eólica. (moradora da comunidade Barra das Moitas durante intercâmbio, 2014)
}

Outro problema verificado é o aumento da população com a vinda de trabalhadores de outras regiões do país para a comunidade, o que fez aumentar a demanda por bens de consumos, por equipamentos públicos e infraestrutura. Investimentos em postos de saúde, educação, moradia e saneamento são colocados em segundo plano ou desconsiderados no planejamento publico. Há expressivo aumento da geração de resíduos sólidos, da demanda por vias de acesso e o aumento do trânsito de carros e caminhões pesados comprometendo as estradas da região.

As estratégias fundamentais utilizadas pelas empresas são a desinformação ou apresentação de informações confusas, e promessas de implantação de equipamentos públicos (em substituição as responsabilidades do poder público) e de geração de empregos para a população local. Porém, as contrapartidas e investimentos públicos por meio do BNDES e Banco do Nordeste não são esclarecidas, bem como a isenção de ICMS praticada pelo poder municipal. Recursos estes que fazem a diferença no orçamento municipal diante das demandas de infraestrutura da população.

A chegada de expressivo números de trabalhadores de fora trás também aumento da violência, exploração sexual e interferência na auto-estima da juventude local. Os empregos oferecidos não atendem a comunidade, são temporários (apenas o período de implantação do mesmo) e precarizados. Após o processo de instalação, apenas uma pessoa é contradada como vigilante para impedir o acesso 
dos comunitários às áreas que antes eram públicas e de uso coletivo e estão ocupadas pelos complexos eólicos. O relato a seguir aponta elementos sobre a relação de trabalho durante a implantação dos parques eólicos.

Após o processo de trabalho passei a ver que eram espinhos, eu fui vitima e não é suficiente para sobreviver, não tem reconhecimento, enquanto ta do lado deles, tudo certo, mas querem subordina, propostas falas, trabalhei 6 meses e fomos mal tratados e simplesmente queriam que fosse uns escravos, para eles, nove da noite cansaço, humilhação, hora extra nunca pagaram, adoece na empresa e não tinha mais apoio, quando voltei fui jogado fora. (ex-trabalhador do Complexo Eólico em Barra das Moitas, 2014).

O que se verifica é a assimetria entre os interesses das empresas e estratégias de produção e reprodução praticadas historicamente pelas comunidades. Há o processo de transformações territoriais que impõe à população a construção de um território do medo, da intranquilidade, da insegurança. As comunidades locais passam a conviver com possibilidades e com fatos que impõe rotas de fuga, riscos de acidentes, fios expostos nas dunas e o barulho constante dos aerogeradores.
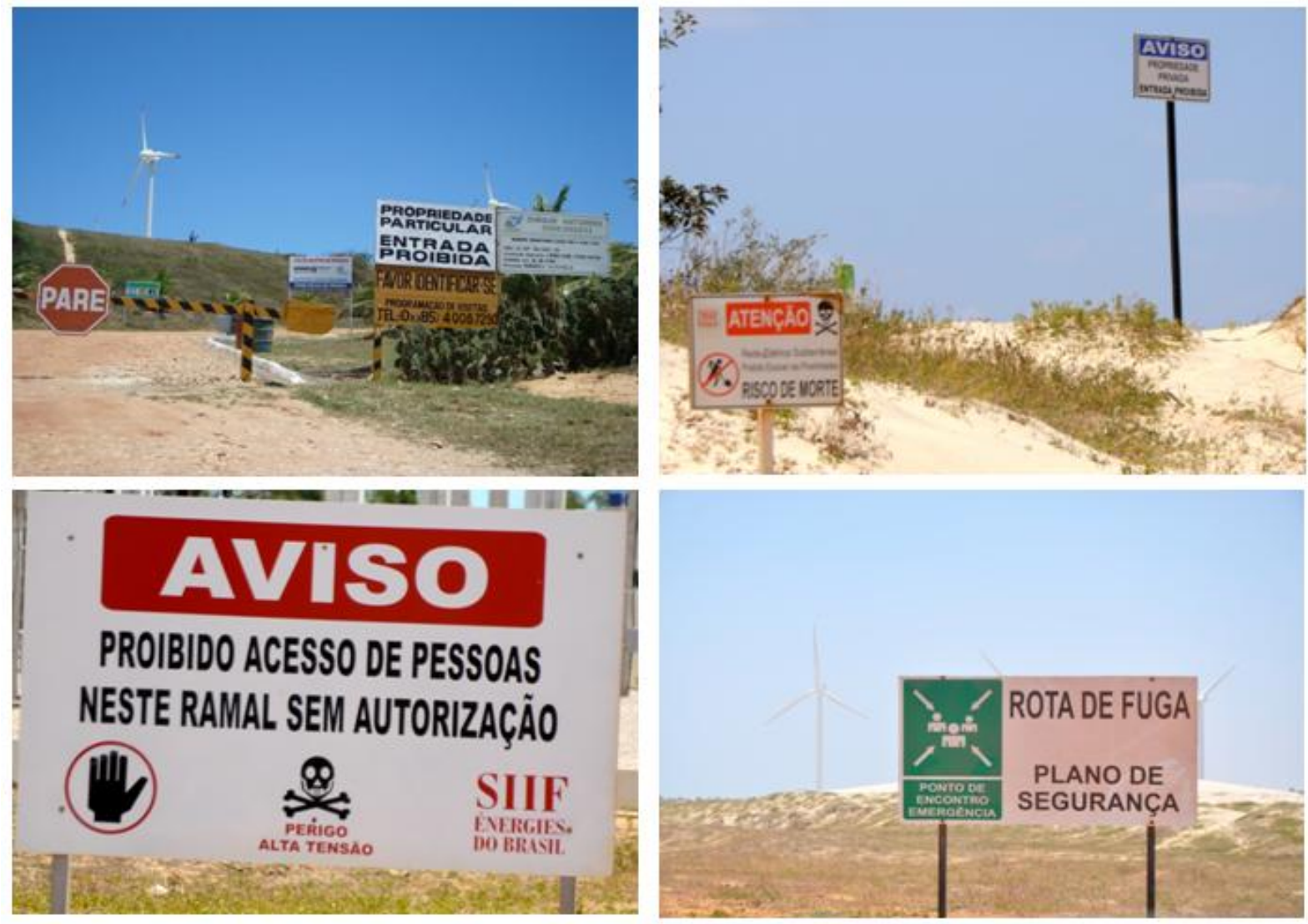

Figuras 02 à 05: Placas indicativas de proibição de passagem, de perigo, insegurança e rotas de fuga instaladas em áreas de implantação de parques eólicos na Zona Costeira do Ceará.

Fotos: Jeovah Meireles, 2014 
Os problemas sociais e ambientais foram identificados durante o Seminário, cujo intercâmbio entre as experiências das localidades compuseram uma expressiva estratégia de elaboração de planos de ação para conter os impactos cumulativos decorrentes do avanço da implantação dos Complexos Eólicos na região costeira do Ceará. O Mapa abaixo apresenta um panorama do processo de expansão dos parques eólicos na Zona Costeira do Ceará o que revela uma intensificação dos impactos e questionamentos quanto ao não reconhecimento do caráter cumulativo desses impactos para a dinâmica dos territórios costeiros.

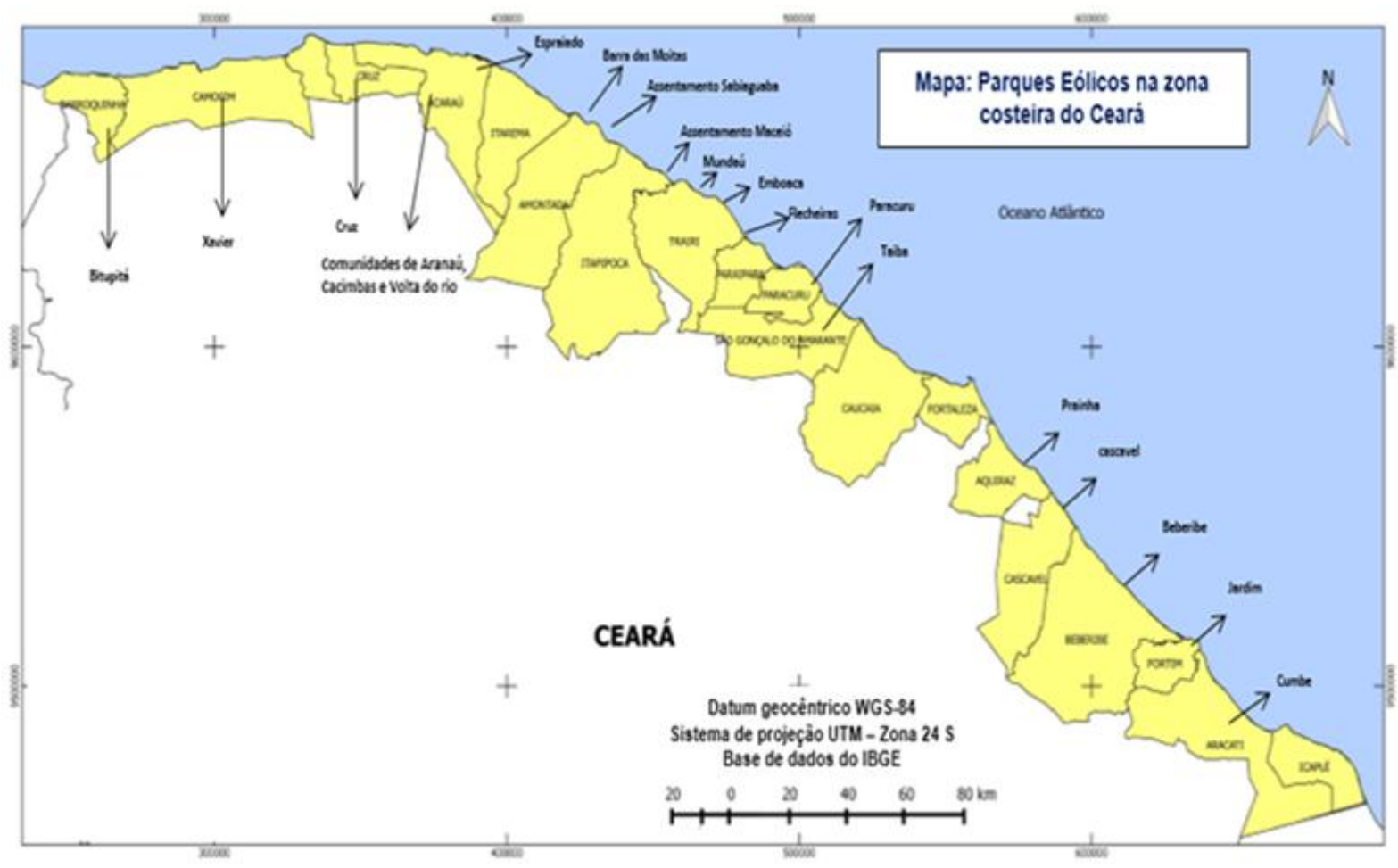

Figura 06 - Fonte: Elaboração própria 2014. Base da Cartografia. Digitalização: Laboratório de Geoprocessamento - Departamento de Geografia - UFC, 2014.

A negação ao acesso à informação e inequidade ambiental do processo de implantação dos empreendimentos revelam-se para a população como principais pontos a serem debatidos e questionados durante as lutas e resistências contra as injustiças ambientais provocados pela instalação dos parques eólicos.

Neste sentido, temos o caso da Comunidade do Cumbe, no litoral leste do Ceará, que ao fazer uma manifestação contra a instalação dos parques de energia eólica no campo de dunas móveis da comunidade, no ano de 2009, fechando a via de acesso ao parque por 19 dias, denunciando as estratégias empresariais de 


\title{
VIANA, L. A.; NASCIMENTO, J. L. J.; MEIRELES, A. J. A. \\ COMPLEXOS EÓLICOS E INJUSTIÇAS AMBIENTAIS: \\ MAPEAMENTO PARTICIPATIVO E VISIBILIZACÃO DOS CONFLITOS \\ PROVOCADOS PELA IMPLANTAÇÃO DE PARQUES EÓLICOS NO CEARÁ
}

induzir o conflito interno, desestruturar a organização social local, e inviabilizar as relações sociais com os bens não comerciais. A ação realizada pela Comunidade do Cumbe torna-se referência para ampliação do debate sobre a questão energética no Ceará e que no âmbito nacional dialoga com demais movimentos que questionam e constroem fundamentos para desconstrução da ideia de energia limpa: para quê e para quem? Sobre o caso da comunidade do Cumbe, Xavier (2013) aponta ainda que,

\begin{abstract}
A implantação dessas usinas, no entanto, não esta sendo um processo ausente de conflitos. As alterações na paisagem, no meio ambiente, e principalmente no direito de ir e vir - com a privatização de extensas áreas, que historicamente são utilizadas pelas comunidades litorâneas do estado têm ocasionado disputas entre os empreendedores e as populações nativas. No caso específico do Cumbe, essas discussões foram agravadas devido à descoberta de vários sítios arqueológicos nas dunas onde foram colocados os aerogeradores. Outro aspecto que intensificou as altercações a respeito desse acontecimento foi 0 fato da empresa responsável peloempreendimento, amparada pela Resolução CONAMA no 279/20017, ter providenciado apenas a RAS (Relatório Ambiental Simplificado). O relatório foi elaborado em dezembro de 2002, ou seja, seis anos antes do início da implantação da usina em 2008. No Relatório Ambiental Simplificado, não existe a exigência de um diagnóstico arqueológico na área do empreendimento, diferente no disposto no EIA/RIMA (Estudo de Impacto Ambiental e Relatório de Impacto Ambiental) (XAVIER, 2013, p. 10 - 11).
\end{abstract}

A concepção de modernidade nos dias atuais está pautada na perspectiva econômica prioritariamente. Essa percepção torna-se mais evidente quando comparadas as realidades vividas nas comunidades que desenvolvem atividades tradicionais e como acontecem as transformações territoriais mediante os impactos ocasionados por projeto de desenvolvimento, dito "modernizadores", pautado no discurso do "progresso". A partir dos relatos sobre o antes e o depois das relações com o território pode-se identificar os processos de vulnerabilização das comunidades e as conseqüências da invasão aos espaços públicos de uso coletivo, que hoje se encontram privatizados para favorecer aos interesses do mercado, explorando a força de trabalho local e com isso trazendo doenças ocupacionais e aumento de casos de violência, exploração sexual, gravidez indesejada, dentre outros aspectos. A união das lutas dos povos tradicionais e movimentos sociais por justiça socioambiental têm dado visibilidade às ameaças e resistências desses grupos sociais que são impactados no processo. O Estado executa uma papel fundamental na garantia de implantação de empreendimentos degradantes e 
promotores de desigualdade social, através de estratégias de flexibilização das leis e sucateamento dos órgãos fiscalizadores, no não reconhecimento dos territórios indígenas, quilombolas e das comunidades tradicionais, da não prioridade quanto a reforma agrária, ao favorecimento privado por meio de financiamentos, a destruição da biodiversidade dos ecossistemas costeiros e das diversas comunidades do campo no atendimento dos interesses dos grupos financeiros capitalistas. A financeirização dos territórios tradicionais, a destruição do meio ambiente, a falta de acesso às informações e o tratamento diferenciado pelos órgãos de justiça são os principais problemas relatados pelos povos tradicionais que seguem em luta pelos seus direitos.

Nesse sentido, as comunidades apontam que realizar ações articuladas de pressão e controle social nos processos de implantação desses empreendimentos são aspectos importantes no processo de resistência das comunidades que lutam por um território livre das ameaças econômicas. A visibilização e afirmação de suas culturas e dos modos de fazer, das práticas cotidianas da população mostram que existem-alternativas ao modo de produção hegemônico e que estas podem se constituir efetivamente em possibilidade de perpetuação da existência humana no planeta.

\section{CONSIDERAÇÕES FINAIS}

É importante considerar nessa dinâmica a conduta de intervenção e os conflitos socioambientais que se formam em torno da segregação e das imposições de poder sobre o planejamento e implantação de grandes obras de infraestrutura. Há uma percepção social local diante da intervenção externa que altera não só a paisagem, mas os modos de vida do cotidiano na comunidade.

O desenvolvimento na perspectiva da economia hegemônica desqualifica e desconsidera o modo de vida das comunidades tradicionais sendo muitas delas invisibilizadas no processo de implantação dos empreendimentos. São diversas as estratégias adotadas pelas empresas que por meio da desarticulação social e de difusão de informações infundadas iludem a população e interferem no seus modos de vida, lidando com os conflitos com discurso de que tal progresso é inevitável e 
que as comunidades são obrigadas a compreender as intervenções em favor de um desenvolvimento que favorece aos interesses econômicos.

Os movimentos sociais, comunidades tradicionais e pesquisadores tem adotado uma série de estratégias para conter os avanços do modelo de implantação dos complexos eólicos, sobretudo na zona costeira, por meio das práticas de intercâmbio e mapeamento participativo dos conflitos, dos impactos e das táticas de implantação dos complexos. Estratégias estas que acumulam elementos e argumentos que se constituem em possibilidades de fundamentação na desconstrução do mito da energia "limpa".

O que ocorre é um problema multidimensional, mas as questões são tratadas apenas pela ótica da dimensão econômica ou sob influência desta. Um diálogo interdisciplinar sobre esses problemas faz-se necessário, mas é importante considerar que há um desenvolvimento pautado na perpetuação dos valores e objetivos do modo de produção capitalista que influencia as perspectivas de atuação social, política, cultural e acadêmica que conduz processos de vulnerabilização dos grupos sociais cujas formas de vida seguem em lógica diferenciada do modelo econômico hegemônico.

\section{Referências}

ACSELRAD, Henri.; MELLO, Cecília Campelo Amaral.; BEZERRA, Gustavo das Neves. O que é Justiça Ambiental? Rio de Janeiro: Garamond, 2009.

ACSELRAD, Henri.; BEZERRA, Gustavo das Neves. Desregulação, deslocalização e conflito ambiental - considerações sobre o controle das demandas sociais no Brasil contemporâneo. XIII Encontro da Associação Nacional de Pós-graduação e Pesquisa em Planejamento Urbano e Regional. Florianópolis, SC. 25 a 29 de maio de 2009.

ACSELRAD, Henri (org). Cartografias sociais e território. Rio de Janeiro: UFRJ, IPPUR, 2008.

ASSIS, Wendel Fisher Teixeira. In-visibilizar populações e legitimar inequidades: a apropriação do discurso do desenvolvimento sustentável na publicidade do Setor Elétrico. In: ZHOURI, A (org.). As tensões do lugar: hidrelétricas, sujeitos e licenciamento ambiental. Belo Horizonte: UFMG, 2011.

AGÊNCIA NACIONAL DE ENERGIA ELÉTRICA - ANEEL. Atlas de Energia Elétrica no Brasil. 2ed. Brasília. 2005 
BRASIL. Política Energética Nacional. Lei 9478/1997.Republica Federativa do Brasil, DF. 1997.

BRISSAC, Sergio Goes Telles; SANTOS, Márcio Martins dos. Empreendimentos que impactam terras indígenas: um olhar sobre a atuação do MPF, a partir de situações no Tocantins e no Ceará. 29ำ Reunião Brasileira de Antropologia /RBA: Natal, 2014.

FREITAS, Roberta Jéssica Nascimento. Energia Eólica: os conflitos socioambientais gerados pela implantação dos parques eólicos no Litoral do Ceará. 6ํㅡㄹ Encontro ANPPAS. Belém, 2012.

HARVEY, David. O Novo Imperialismo. São Paulo: Ed. Loyola, 2004.

LISBOA, Marijane. Em nome do desenvolvimento: um fundamento pouco sólido para resolução de conflitos. In: ZHOURI, Andréa; VALENCIO, Norma (orgs.). Formas de matar, de morrer e de resistir: Limites da resolução negociada de conflitos ambientais. Belo Horizonte: Editora UFMG, 2014, p. 51-78.

MARQUES, Janaína. Governo vai atualizar atlas eólico por cerca de $\mathbf{R} \$ \mathbf{6 0 0} \mathbf{m i l}$. 2014.

Disponível em

http://www.opovo.com.br/app/opovo/economia/2014/08/27/noticiasjornal economia,3304496/governo-vai-atualizar-atlas-eolico-por-cerca-de-r-600mil.shtml.Acesso em 22/06/2015.

MEIRELES, Antônio Jeovah de Andrade. Parecer Técnico Impactos ambientais em áreas de preservação permanente (APP'S) promovidos no campo de dunas da Taíba pela usina eólica Taíba Albatroz. Fortaleza, 2008.

- Danos socioambientais originados pelas usinas eólicas nos campos de dunas do Nordeste brasileiro e critérios para definição de alternativas locacionais. In: Confins, Revista Franco-Brasileira de Geografia [Online], 11|2011. Disponível em: http://confins.revues.org/6970. Acesso em 22/06/2015.

MILANEZ, Bruno; SANTOS, Rodrigo Salles Pereira dos. Neodesenvolvimentismo e neoextrativismo: duas faces da mesma moeda?. In: 37o. Encontro Anual da ANPOCS, 2013, Águas de Lindóia. Anais do 37o. Encontro Anual da ANPOCS, 2013.

MINISTĖRIO DE MINAS E ENERGIA. Plano Decenal de Expansão de Energia 2023. Brasília: EPE/MME, 2014.

PAULA, João Antônio de. Crise econômica e reiteração do capitalismo dependente no Brasil. In: ALMEIDA et al. Capitalismo Globalizado e Recursos Territoriais: fronteiras da acumulação no Brasil contemporâneo. Rio de Janeiro: Lamparina, 2010. 
REDE BRASILEIRA DE JUSTIÇA AMBIENTAL. Princípios da justiça ambiental. Disponível em: http://www.justicaambiental.

org.br/_justica ambiental/pagina.php?id=229. Acesso em 22/06/2015.

PORTO, Marcelo Firpo de Souza, FINAMORE, Renan, FERREIRA, Hugo. Injustiças da sustentabilidade: Conflitos ambientais relacionados à produção de energia "limpa" no Brasil. Revista Crítica de Ciências Sociais. 2013. Disponível em: http://rccs.revues.org/5217. Acesso em 30/04/ 2015.

PORTO, Marcelo Firpo de Souza; MILANEZ, Bruno. Eixos de desenvolvimento econômico e geração de conflitos socioambientais no Brasil: desafios para a sustentabilidade e a justiça ambiental. Revista Ciência e Saúde Coletiva. Vol.14, no.6. 2009.

PORTO-GONÇALVES, Carlos Walter. A Ecologia Política na América Latina: reapropriação social da natureza e reinvenção dos territórios. Florianópolis, SC:

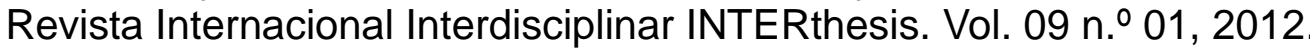

SECRETARIA DA INFRA-ESTRUTURA DO ESTADO DO CEARÁ (SEINFRA). Atlas do Potencial Eólico do Estado do Ceará. Fortaleza. 2001.

XAVIER, Patrícia Pereira. Valorização e preservação do patrimônio arqueológico na Comunidade do Cumbe - Aracati-CE. Dissertação (Mestrado Profissional em Patrimônio Cultural) - Instituto do Patrimônio Histórico e Artístico Nacional: Rio de Janeiro. 2013. 